\title{
Measuring Emigration of Human Thymocytes by T-Cell Receptor Excision Circles
}

\author{
Ping Ye \& Denise E. Kirschner* \\ Department of Microbiology and Immunology, The University of Michigan Medical School, \\ Ann Arbor, MI
* Address all correspondence to Denise E. Kirschner, Ph.D., 6730 Medical Science Building II, Ann Arbor, MI 48109-0620; Phone: (734) 647-7722; Fax: (734) 647-7723; E-mail: kirschne@umich.edu. \\ Referee: Daniel Douek, M.D., Ph.D., Chief, Human Immunology Section, NIH Vaccine Research Center, Room 3509,40 Convent \\ Drive, Bethesda, MD 20892
}

\begin{abstract}
Recent advances in characterizing thymic function confirm the importance of thymus to T-cell diversity in the periphery of both children and adults during both health and disease. Lack of a marker to identify human recent thymic emigrants (RTEs) is the biggest hurdle to accurately characterizing and quantifying thymic output. T-cell receptor excision circles (TRECs) are used as an assay to measure RTE levels. Controversy exists, however, as to whether TREC concentrations reflect the number of RTEs or are mainly altered by peripheral Tcell division and death. In this review, we first summarize recent data on the human thymus and RTEs. On the basis of both experimental and mathematical analyses, we characterize factors that influence TREC dynamics in the periphery and elucidate primary elements that induce a decline in TREC concentrations during normal aging and HIV-1 infection. Our findings suggest that T-cell dynamics are key to the accuracy of TREC concentrations as a useful measurement of human RTEs.
\end{abstract}

KEY WORDS: thymus, recent thymic emigrants, T-cell dynamics, aging, HIV-1 infection, mathematical model.

\section{INTRODUCTION}

The population of peripheral blood $\mathrm{T}$ cells is maintained in relative homeostasis over the life of the human host. ${ }^{1}$ Both the output of recent thymic emigrants (RTEs) from the thymus and the proliferation of $\mathrm{T}$ cells already present in the periphery contribute to the total T-cell pool. ${ }^{2}$ Because of thymic involution, however, the relative contributions of the thymus and proliferating $\mathrm{T}$ cells to maintaining homeostasis of peripheral $\mathrm{T}$ cells gradually switch during the human lifespan. It is generally assumed that in infants peripheral $\mathrm{T}$ cells are maintained predominantly through thymic output of RTEs, whereas in adults T-cell numbers are predominantly supplemented through the expansion of existing peripheral T cells (Fig. 1). ${ }^{2}$

Aside from quantitative differences between these two sources of newly generated $\mathrm{T}$ cells, qualitative differences exist as well. ${ }^{1}$ Newly gen-

\section{ABBREVIATIONS}

RTEs, recent thymic emigrants; TCR, T-cell receptor; TRECs, T-cell receptor excision circles; TES, thymic epithelial space; PVS, thymic perivascular space; TN, CD3-CD4-CD8- triple negative; ITTP, CD3-CD4 ${ }^{+} \mathrm{CD} 8$ intrathymic $\mathrm{T}$ progenitor; $\mathrm{DP}, \mathrm{CD} 3{ }^{+} \mathrm{CD} 4{ }^{+} \mathrm{CD} 8{ }^{+}$double positive; $\mathrm{SP} 4, \mathrm{CD} 3{ }^{+} \mathrm{CD} 4{ }^{+} \mathrm{CD} 8{ }^{-}$single positive; $\mathrm{SP} 8$, CD ${ }^{+}{ }^{+}$D 4-CD8 ${ }^{+}$single positive; sjTREC, signal-joint TREC; cjTREC, coding-joint TREC; PBMCs, peripheral blood mononuclear cells; HAART, highly active anti-retroviral therapy.

$1040-8401 / 02 / \$ 5.00$

(C) 2002 by Begell House, Inc. 
Children $\quad$ Ooung Adults Adults

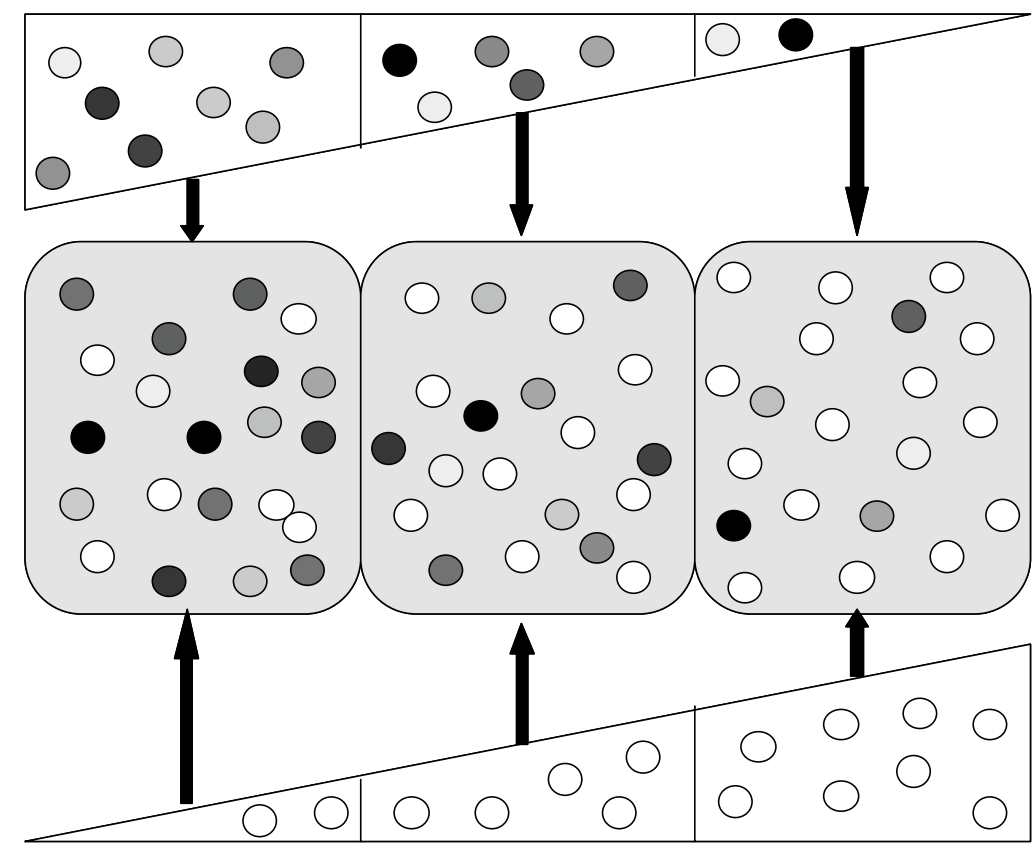

Thymic Output of RTEs

Peripheral T Cell Pool

Peripheral T cell Proliferation

FIGURE 1. Both thymic output of RTEs and peripheral T-cell proliferation contribute to peripheral T-cell homeostasis. Thymic output of T cells with diversified TCR gradually decreases over age, whereas peripheral T-cell proliferation augments the supply of T cells with limited TCR diversity to the peripheral T-cell pool to maintain T-cell homeostasis. Cells labeled with different shades represent diversified TCR repertore provided by the thymus, whereas cells labeled with the same shades represent a limited TCR repertoire provided through peripheral T-cell proliferation.

erated $\mathrm{T}$ cells within the thymus undergo $\mathrm{T}$-cell receptor (TCR) rearrangements, providing a peripheral T-cell repertoire diversity that is necessary to respond to numerous potential neoantigens. New T cells generated through existing peripheral T-cell proliferation preserve the phenotype of their progenitors and respond to a limited number of encountered antigens (Fig. 1). Therefore, recently exported thymocytes are critical to sustaining both functionality and size of the peripheral $\mathrm{T}$-cell pool. Thymic generation of new T cells is especially important under immunodeficiency conditions, such as HIV-1 infection, hemopoietic stem cell transplantation, and chemotherapy, since it allows for recovery of T-cell-mediated immunity better than if the recovery were only through expansion of pre-existing $\mathrm{T}$ cells. ${ }^{1,3}$

The term RTE in humans generally refers to $\mathrm{T}$ cells that have undergone only a few cellular divisions after leaving the thymus. A central di- lemma for characterizing human thymic function is the lack of phenotypic markers for RTEs. Thus, experimental quantification of the number of RTEs exported from the thymus is not yet possible. Currently, measurement of T-cell receptor excision circles (TRECs) has been extensively used to represent RTE levels in both health and disease. $^{4-9}$ TRECs are excised DNA fragments generated during TCR gene rearrangement in thymocytes. They are exported from the thymus to the periphery within RTEs as episomal DNA. Thus, TREC concentrations in the periphery could reflect RTE numbers. TRECs are stable and are not duplicated during mitosis; therefore, TREC concentrations are diluted out with each cell division. Controversy exists as to whether TREC concentrations can be used as an accurate measure of RTEs, since peripheral T-cell dynamics could influence TREC concentrations as well. ${ }^{4,10-12}$ In this review, we characterize human thymic func- 
tion, elucidate concepts of RTEs and TRECs, and explore the controversy of using TREC concentrations as a marker for RTEs.

\section{THE HUMAN THYMUS}

The human thymus is the primary lymphoid organ that provides a unique environment for $\mathrm{T}$-cell education and development, a process known as thymopoiesis. The thymic epithelial space (TES), where thymopoiesis occurs, contains mainly thymocytes and stromal cells. ${ }^{13}$ Stromal cells include epithelial cells, macrophages, and dendritic cells supplying both direct cell contact to thymocytes and soluble molecules important for thymocyte development. ${ }^{14}$ The thymic perivascular space (PVS) is the nonfunctional thymic tissue surrounding the TES region, comprised mainly of vessels and connective tissue. ${ }^{13}$

Thymopoiesis occurs in the TES region starting from the second trimester of gestation and has been detected up to 107 years of life. ${ }^{13,15}$ Bone marrow progenitor cells migrate into the thymus and differentiate into $\mathrm{CD}^{-}{ }^{-} \mathrm{CD} 4^{-} \mathrm{CD}^{-}$triple negative (TN) cells. TN cells then sequentially differentiate into $\mathrm{CD}^{-}{ }^{-} \mathrm{CD} 4^{+} \mathrm{CD} 8^{-}$intrathymic progenitor (ITTP) cells and subsequently $\mathrm{CD}^{+}{ }^{+} \mathrm{CD} 4{ }^{+} \mathrm{CD} 8{ }^{+}$double-positive (DP) cells. Approximately $95 \%$ of DP cells undergo death due to positive or negative selection, whereas the remaining cells further differentiate into either $\mathrm{CD}^{+}{ }^{+} \mathrm{CD} 4{ }^{+} \mathrm{CD} 8{ }^{-}$single-positive (SP4) or $\mathrm{CD}^{+}{ }^{+} \mathrm{CD} 4{ }^{-} \mathrm{CD}^{+}{ }^{+}$single-positive (SP8) cells. ${ }^{16}$ Mature SP4 and SP8 cells emigrate from the thymus into the periphery as RTEs (Fig. 2).

By the end of the 1st year of life, the thymus reaches maximal size and continues to supply $T$ cells with diversified TCR to the periphery, thus establishing the peripheral $\mathrm{T}$-cell pool. ${ }^{13}$ Thymectomy in the 1st month of life may result in some degree of immunodeficiency, as evidenced by significantly lower numbers of $\mathrm{T}$ cells and $\mathrm{T}$-cell subsets, and diminished T-cell responses. ${ }^{17}$ During aging, the TES region shows a continuous involution, starting from the 1st year until the end of life, whereas the PVS region expands in size. ${ }^{15}$ Although the size of the human thymus remains unchanged, the absolute number of thymocytes dramatically decreases as the TES region shrinks.
Evidence supporting the involution of the adult thymus comes from studies of children and adults following cancer therapy and stem-cell transplantation. Children tend to have a much faster T-cell reconstitution than adults, suggesting a more active thymus. ${ }^{6,18}$ The adult thymus, however, is still actively engaged in thymopoiesis contributing new $\mathrm{T}$ cells to the periphery. ${ }^{19,20}$

Thymic involution during aging affects human thymopoiesis quantitatively rather than qualitatively. Thymocyte subset distributions in adults are similar to those observed in the fetus, and adult thymocytes continue to undergo TCR rearrangement at levels similar to those of the fetal thymus on a per thymocyte basis. ${ }^{19}$ Further, thymic stromal cells remain active, providing signals for thymocyte survival and maturation throughout life. ${ }^{14}$ By contrast, murine thymopoiesis is less efficient during aging, as evidenced by declining TREC concentrations within thymocytes with age. ${ }^{21}$

To capture the dynamics of human thymocyte subsets over an 80-year lifespan, we developed a computational model mostly based on human clinical and experimental data. ${ }^{10}$ The model demonstrates that five thymocyte subsets increase to their maximal values at age one and then decrease at a rate after that of approximately $5 \%$ per year (Fig. 3A).

IL-7 secreted by stromal cells in the thymus appears to play a role in the multiple stages of thymocyte development. ${ }^{22}$ By examining the effects of exogenous IL-7 on the generation of TRECs in the human thymus, one study has demonstrated that IL-7 has a direct effect on increasing TCR $\alpha \beta$ gene rearrangement. ${ }^{23}$ IL-7 administration to young mice also induces elevated TREC concentrations in the thymus, which represents increased thymopoiesis. ${ }^{21}$ These data suggest the potential use of IL-7 for enhancing thymic output of RTEs. Further, treatment of HIV-1-infected individuals with human growth hormone has been associated with a marked increase in thymic mass and circulating naive $T$ cells, indicating the role of growth hormone in enhancing thymopoiesis as well. ${ }^{24}$

In order to reconstitute $\mathrm{T}$-cell immunity, thymus transplantation has been performed in infants with DiGeorge syndrome, a congenital thymic dysfunction with severely reduced $\mathrm{T}$-cell function, ${ }^{5}$ and in adults with HIV-1 infection..$^{25}$ 


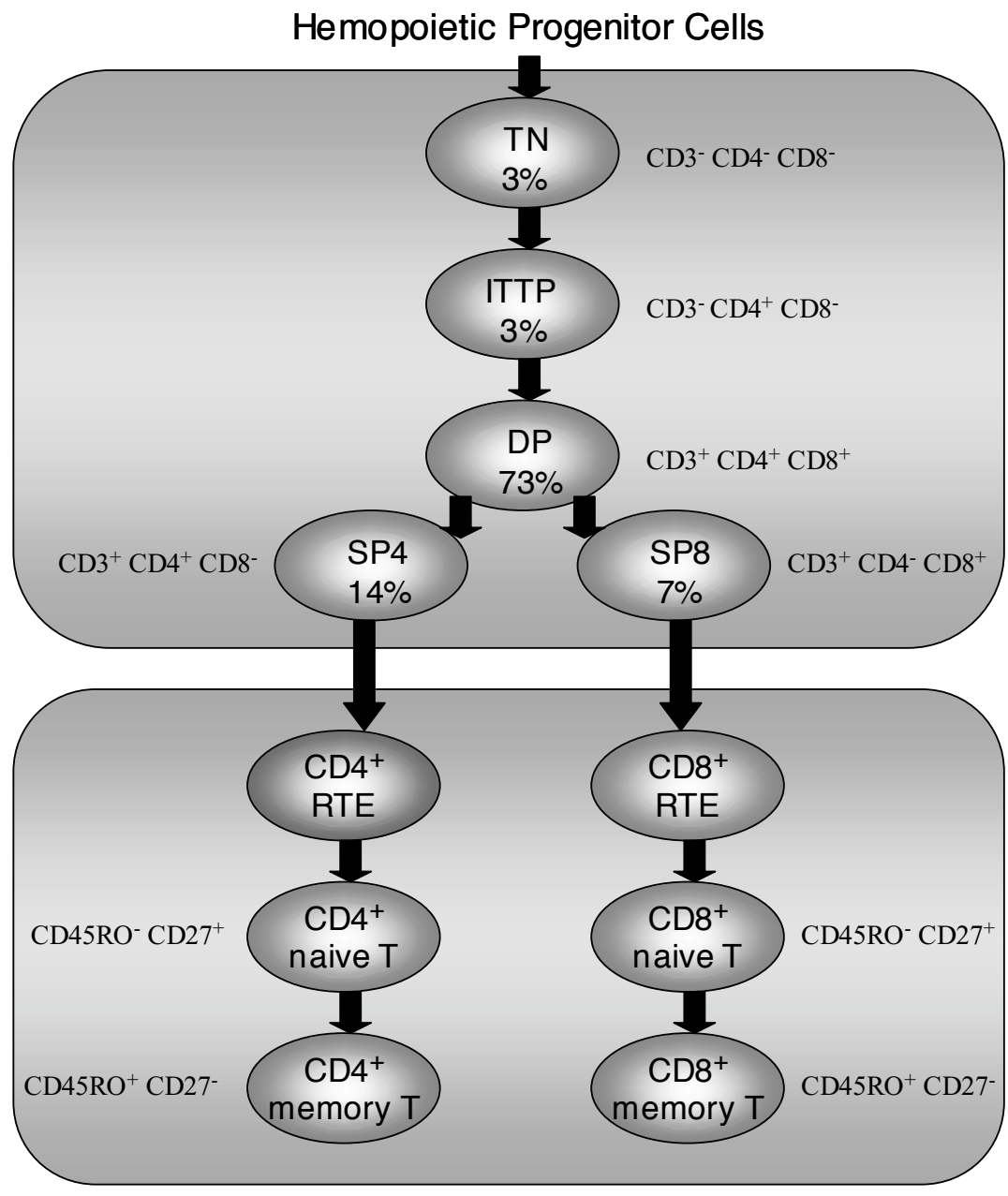

\section{THYMUS}

\section{PERIPHERY}

FIGURE 2. Thymopoiesis within the thymus followed by T-cell maturation in the periphery. Hemopoietic progenitor cells migrate into the thymus and follow a series of maturation stages, including TN cells, ITTP cells, DP cells, and SP4 or SP8 cells. Thymocyte percentage is labeled for each subset. 16,19 Mature thymocytes are exported into the periphery to become RTEs, which further mature/develop into naive T cells. Upon antigen stimulation, naive T cells differentiate into memory T cells. Phenotypic markers are used to identify different subsets of thymocytes and peripheral T cells, except RTEs. ${ }^{11,16}$

Results from patients with DiGeorge syndrome demonstrate that transplantation of thymic tissue can promote successful immune reconstitution. ${ }^{5}$ Thymic allografts, however, are rejected in HIV-1infected patients within 2 months, and no difference in restoration of $\mathrm{T}$-cell function in the transplant recipients is observed as compared with controls. ${ }^{25}$ The contradictory results yielded from thymus transplantation studies in these two populations may be related to the differences in recipients' age and disease status. Nevertheless, thymus transplantation may have potential use in adults with involuted thymus or in patients with immunodeficiency to augment thymic output of new $\mathrm{T}$ cells to the periphery.

\section{RECENT THYMIC EMIGRANTS}

RTEs refer to newly generated $\mathrm{T}$ cells that are recently exported from the thymus into the periphery. The ability to measure the number of RTEs would be invaluable for studying the thymic contribution to the establishment of peripheral 
T-cell repertoire as well as naive T-cell regeneration. Since no phenotypic marker has been identified for human RTEs, however, it is not yet possible to quantify the number of RTEs experimentally. Our computational model provides an estimation for the number of $\mathrm{CD}^{+}$and $\mathrm{CD} 8^{+}$ RTEs exported from the thymus per day to the periphery (Fig. 3B). ${ }^{10}$ Because of the lack of data on the half-life and circulation patterns of human RTEs, even a computational model cannot estimate the absolute number of human RTEs in blood and lymph tissue for different ages.

In contrast to those of humans, RTEs have been identified by phenotypic markers in chicken, rat, and mouse models. In chicken, the T-cell marker $\mathrm{chT}^{+}$is used to define RTEs. They are evenly distributed among peripheral T-cell compartments, including blood, spleen, and intestinal epithelial. The half-life of chicken chT1+ RTEs is about 3 days, and their complete loss in the periphery occurs in 1 month, as observed by experiments using thymectomized chicken ${ }^{26}$ In rats, $\mathrm{CD}^{+}{ }^{+} \mathrm{RTE}$ s are defined as bearing $\mathrm{CD}_{45 \mathrm{RC}^{-}}$ $\mathrm{CD}^{+} 0^{+}$and can be identified in blood, the spleen, and lymph nodes. The percentage of rat RTEs in blood is $15 \%$ in rats 1 month of age, which is comparable to other compartments, suggesting RTEs travel through the periphery similar to mature $\mathrm{T}$ cells. It takes 1 week on average for rat RTEs to be incorporated into the naive T-cell pool. ${ }^{27}$ Another study suggests that Thy $1^{+} \mathrm{CD} 45 \mathrm{RC}^{-}$
$\mathrm{RT}^{-}$is the marker for both $\mathrm{CD}^{+}{ }^{+}$and $\mathrm{CD} 8^{+} \mathrm{RTEs}$ in rats. They are also observed to differentiate into mature $T$ cells within 1 week of release from the thymus. ${ }^{28}$ In mice, FITC-labeling of thymocytes and grafting of thymic lobes from congenic Ly5.2+ mice have been used to study RTEs. ${ }^{29}$ Most mouse RTEs persist at least 3 weeks in the periphery, and thymic output of RTEs is not influenced by the size of peripheral T-cell pool nor by increased levels of circulating RTEs. ${ }^{29}$

Several studies have been performed trying to characterize human RTEs, but they have been inconclusive. One phenotypic approach suggests that $\mathrm{CD} 103^{+}$naive $\mathrm{CD} 8^{+} \mathrm{T}$ cells are $\mathrm{CD} 8^{+} \mathrm{RTE}$. These $\mathrm{CD} 103^{+}$cells recirculate through and localize within secondary lymphoid tissues and demonstrate an age- and thymectomy-related decline as would be expected to occur in RTEs because of thymopoiesis. ${ }^{30}$ Another study demonstrates that human cord blood T cells represent RTEs, since they express thymocyte-like characters with regard to rapid rates of apoptosis and enhanced proliferation in the presence of IL-7.31 A third study demonstrates a high enrichment of TRECs in peripheral naive $\mathrm{CD} 45 \mathrm{RA}^{+}$cells coexpressing $\mathrm{CD} 31$ as compared with naive $\mathrm{CD} 45 \mathrm{RA}^{+} \mathrm{CD} 31^{-}$cells, where TRECs can be hardly detected. This implies that a phenotypic marker of CD45RA+CD31+ exists for human RTEs. Furthermore, the percentage of this group of cells declines during aging. ${ }^{32}$ Human RTEs have also been suggested
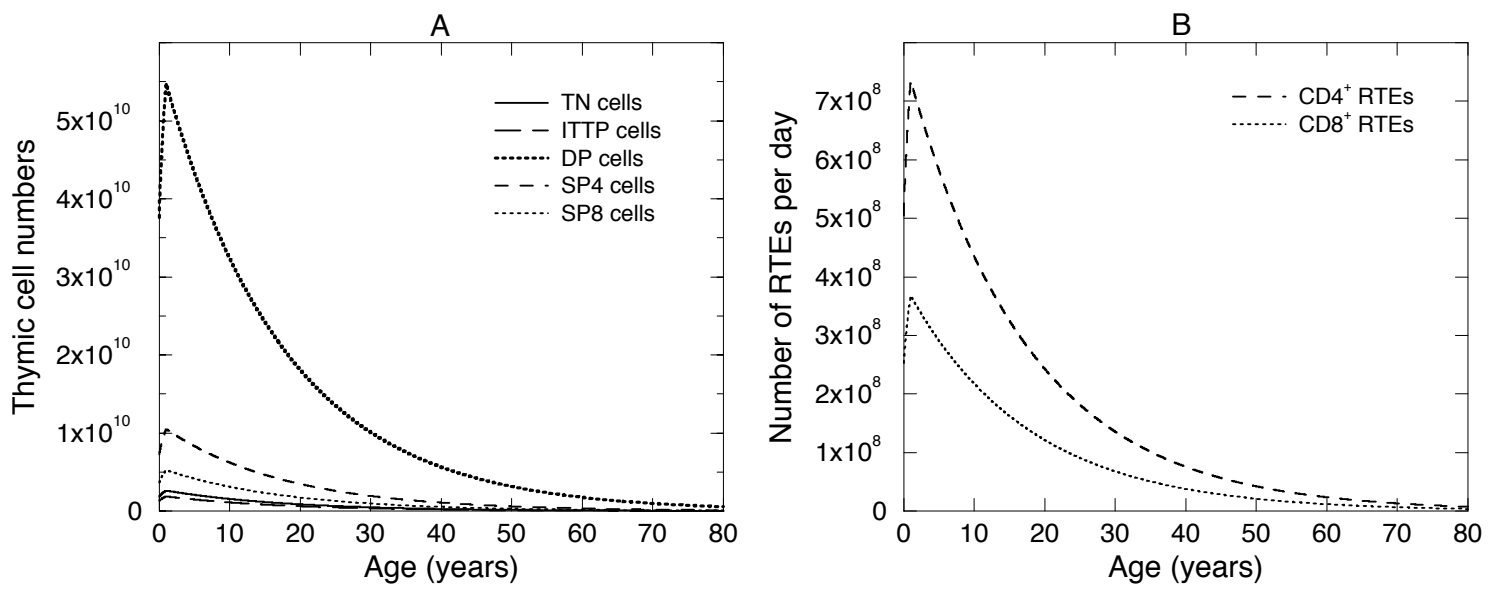

FIGURE 3. Thymocyte subsets and RTE dynamics over an 80-year lifespan. Panel A shows model simulations of five thymocyte subsets. Panel B shows the number of RTEs exported from the thymus per day. (Modified and used with permission from Ref. 10.) 
to home to lymph nodes ${ }^{33,34}$ and to the sites of IL-7 production, such as gut, skin, and liver. ${ }^{35}$

Currently three measurements are used as surrogates of human RTEs in various clinical scenarios, including naive $\mathrm{T}$-cell numbers, thymic volume, and TREC concentrations. ${ }^{4,9,36}$ Concerns exist, however, regarding limitations for each of these three measures. Naive T cells may proliferate, may have a long lifespan, and may be converted back from the memory $\mathrm{T}$-cell class while still retaining a functional memory. ${ }^{3}$ The volume of functional thymic tissue can be measured by computed tomography, ${ }^{37}$ radiographic imaging, ${ }^{18}$ or ultrasound. ${ }^{38}$ Thymic size is a rough estimation of thymic function and represents RTEs based on the assumption that thymic size is proportional to the number of RTEs. TREC concentration has recently become the mostly favored surrogate for the measurement of human RTEs. 4,9,33,39 Interpretations of TREC data, however, have been complicated by $\mathrm{T}$-cell dynamics in the periphery. ${ }^{4,10-12}$ In the next section, we explore TREC generation, measurement, and application to both health and disease.

\section{T-CELL RECEPTOR EXCISION CIRCLES}

\section{A. TREC Generation Within Thymocytes}

Various episomal DNA fragments are generated within thymocytes during TCR gene rearrangement and are defined as TRECs. TRECs are stable and are not duplicated during mitosis. Therefore, their concentration is diluted out after each cell division when they are passed within cells from thymocyte stage through RTE, naïve, and memory T-cell stages. ${ }^{4}$ TREC species that can be used as measurements of RTEs have to satisfy at least two criteria. First, they must be common for every RTE; second, they must be detectable in the periphery. Two TREC species, signal-joint TREC (sjTREC) and coding-joint TREC (cjTREC), suit these requirements and have been used as measurements of human RTEs. ${ }^{9}, 11,33,39$

The TCR $\delta$ gene is located within the TCR $\alpha$ gene locus. For $\alpha \beta$ T cells, the $\alpha$ gene rearrangement is initiated by the deletion of $\delta$ gene from the $\alpha$ gene locus. During the first $\alpha$ gene rearrangement, sjTREC is excised out from the TCR $\delta$ locus through $\delta$ Rec to $\psi J \alpha$ recombination event. The second TREC species, cjTREC, is generated subsequently by $\mathrm{V} \alpha$ and $\mathrm{J} \alpha$ gene rearrangement (Fig. 4). ${ }^{4}$

The $\delta$ gene deletion usually occurs in both alleles. ${ }^{40}$ Several processes to delete the $\delta$ gene from the $\alpha$ locus may take place in the thymus, but $\delta$ Rec$\psi \mathrm{J} \alpha$ is the most prominent rearrangement event. ${ }^{41}$ Therefore, a maximum of 2 copies of sjTREC or cjTREC may exist in every $\alpha \beta$ T cell immediately after the completion of a corresponding rearrangement event (Fig. 5). Experimental data have measured sjTREC and cjTREC concentrations to be 0.17 copies per cell and 1.33 copies per cell, respectively, in human cord blood $\mathrm{CD}^{+}$and $\mathrm{CD}^{+} \mathrm{T}$ cells. ${ }^{4}$ Assuming that cord blood T cells are RTEs, ${ }^{31}$ we calculate that 3 to 4 cell divisions occur within the thymus after rearrangement produces sjTREC, while 0 to 1 cell divisions occur after generation of cjTREC (Fig. 5). Alternatively, if we consider that approximately $80 \%$ of the $\alpha \beta$ T cells have bi-allelic $\delta$ deletion, ${ }^{42}$ and $\delta \operatorname{Rec}-\psi \mathrm{J} \alpha$ rearrangement represents roughly $68 \%$ of $\delta$ gene deletion, ${ }^{41}$ then the number of cell divisions would be less than the above estimate.

Deletion of the $\delta$ locus from the $\alpha$ gene occurs during the DP cell stage, after cell proliferation and before positive and negative selection events. ${ }^{43}$ Therefore, it is expected that DP cells have higher TREC concentrations as compared with other thymocyte subsets. A study using human fetal thymus has demonstrated that the highest level of sjTRECs is present in the CD3- DP cell stage at 1.5 copies per cell, and sjTREC levels in $\mathrm{CD}^{+}$ DP, SP4, and SP8 cells as 0.7, 0.6, and 0.4 copies per cell, respectively. ${ }^{23,30}$ No sjTREC is detected in TN and ITTP subsets. ${ }^{23}$ Data regarding sjTREC levels in macaque thymocytes are different from those from human cells. In the macaque, the highest level of sjTREC is detected in ITTP stage as 0.5 copies/cell. TREC concentrations in TN, $\mathrm{DP}$, and SP4 cells are $0.02,0.3$, and 0.2 copies per cell, respectively. ${ }^{34}$

\section{B. TREC Detection in the Periphery}

One important quantitative distinction that must be made for TREC detection in the periphery relates to the measurement of the amount of 

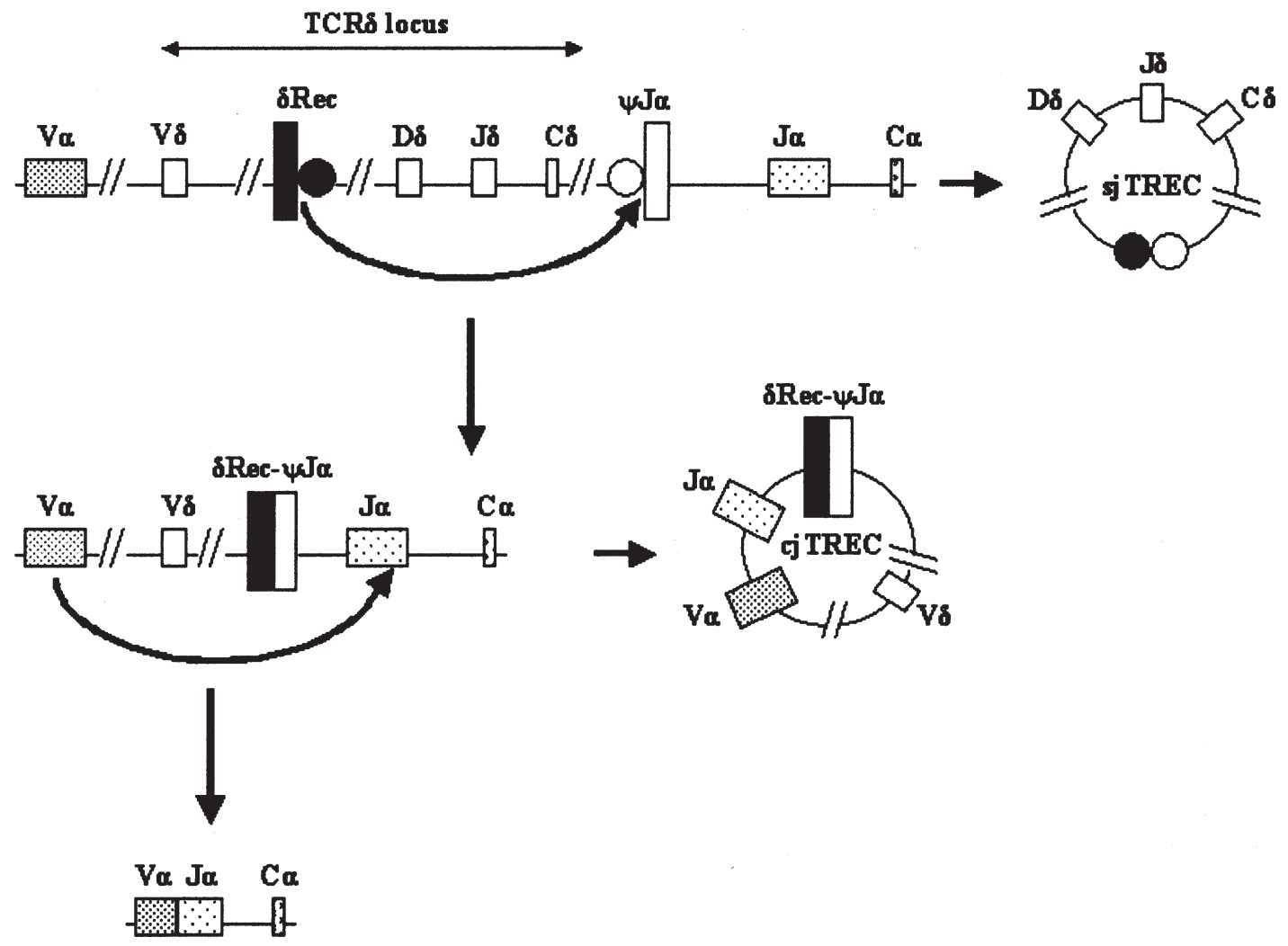

FIGURE 4. Generation of sjTREC and cjTREC during TCR $\alpha$ gene rearrangement. The TCR $\delta$ gene is within the $\alpha$ gene locus. The first $\alpha$ gene rearrangement deletes the $D, J, C$ regions in the TCR $\delta$ locus by ligation of recombination signals flanking the $\delta R e c$ and $\psi J \alpha$ locus, forming sjTREC. A subsequent recombination event leads to the generation of the recominbined $V_{\alpha}-J \alpha-C \alpha$ gene segment and cjTREC containing the $\delta$ Rec and $\psi J \alpha$ locus. (Modified and printed by permission of Macmillan Publishers Ltd. from Ref. 4.)

[[OK?]]

TRECs present either in per unit volume of blood or in a given number of $\mathrm{T}$ cells. We define the first measure as "TREC levels" versus the second measure as "TREC concentrations."

We first explore all potential factors that may influence both TREC levels and TREC concentrations in the periphery, including thymic output of RTEs, T-cell division, T-cell death, TREC degradation, and extrathymic T-cell generation (Table 1). Increased thymic output would increase both TREC levels and TREC concentrations, as new $\mathrm{T}$ cells from the thymus are the major source of TRECs, ${ }^{4,5}$ and TREC concentrations in RTEs are higher than those in peripheral $\mathrm{T}$ cells. ${ }^{30}$ Cell division would not affect TREC levels but would decrease TREC concentrations because of the dilution of TRECs during mitosis. ${ }^{4}$ Dead T cells would be either TRECcontaining or non-TREC-containing. In the former case, TREC levels and TREC concentrations would be expected to decrease, since the death of TREC-containing $T$ cells induces the loss of TRECs within them, whereas in the latter case, TREC concentrations would be expected to increase, but TREC levels would not be affected. TREC degradation within T cells reduces TREC levels as well as TREC concentrations. Extrathymic TCR rearrangements may be another source of TRECs, ${ }^{1}$ elevating TREC levels. If TREC concentrations in extrathymic sites are higher than the periphery, $\mathrm{T}$ cells from extrathymic sites would increase TREC concentrations in the periphery. Otherwise, they would decrease peripheral TREC concentrations (Table 1). Practically speaking, TREC concentrations can be easily monitored in the periphery by drawing small amounts of blood in humans. As the T-cell count in blood is known, TREC levels can be 
calculated from TREC concentrations. ${ }^{44}$ Therefore, we focus on detection of TREC concentrations in the periphery.

TREC analysis in the periphery is considered to be a feasible and practical assay to identify cells of recent thymic origin. ${ }^{4-9}$ Four PCR techniques have been developed to quantify TREC concentrations in the periphery, including quantitative PCR, ${ }^{4}$ real-time PCR, ${ }^{39}$ PCR-ELISA, ${ }^{45}$ and LightCycler technique. ${ }^{46}$ TRECs are detected in $\mathrm{CD}^{+}$and $\mathrm{CD}^{+}{ }^{+} \mathrm{T}$ cells, ${ }^{4}$ peripheral blood mononuclear cells (PBMCs), ${ }^{39}$ and $\mathrm{CD}^{2} 5 \mathrm{RA}^{+}$naive and $\mathrm{CD}_{45 \mathrm{RO}^{+}}$memory $\mathrm{T}$ cells. ${ }^{20}$ Higher TREC concentrations exist in the naive $\mathrm{T}$-cell population as compared with memory $\mathrm{T}$ cells, due to cell division..$^{20}$ One study suggests that total TREC levels in the memory compartment are negligible, since memory cells contain only $2 \%$ of the TREC concentrations of naive $\mathrm{T}$ cells in the same indi- vidual. ${ }^{11} \mathrm{~A}$ gradual decline of TREC concentrations occurs in healthy individuals over their lifespan. ${ }^{4,10,39}$ Interestingly, females contain significantly higher levels of TRECs than males. ${ }^{7}$

Nevertheless, it is still under debate whether TREC concentrations accurately represent thymic activity or are predominantly reflecting peripheral T-cell division and death., ${ }^{40-12}$ Among the above five factors that we have discussed affecting TREC concentrations (see Table 1), TREC degradation would likely be constant, ${ }^{47}$ and the contribution of TRECs arising from extrathymic sites is likely negligible, since no TREC is detected in the periphery of individuals with DiGeorge syndrome. ${ }^{4,5}$ Therefore, changes in RTE levels and peripheral $\mathrm{T}$-cell division and death become the major factors impacting TREC concentrations, all of which need to be considered when interpreting TREC data.

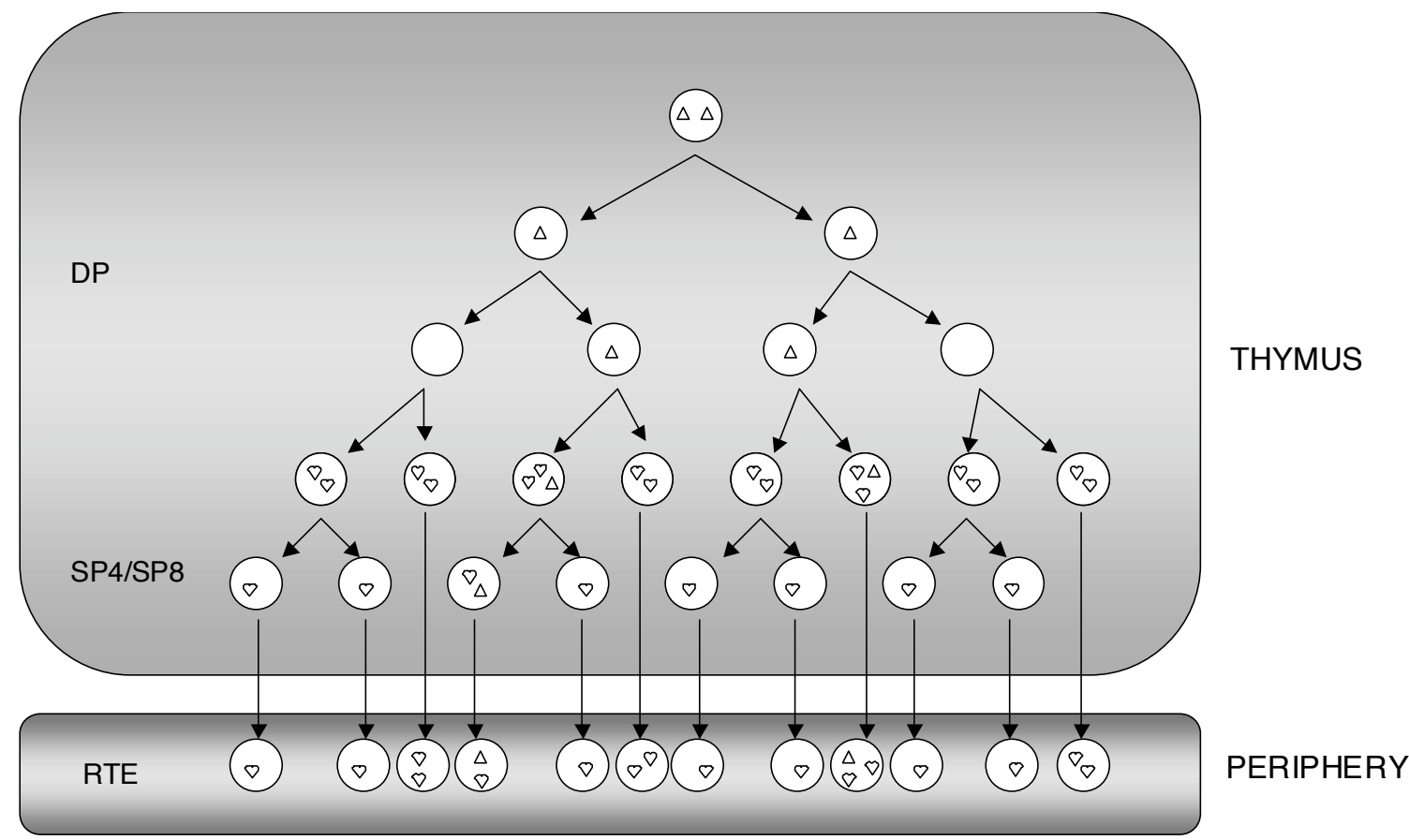

FIGURE 5. sjTREC and cjTREC dynamics from the thymus to the periphery. Both sjTREC (represented by triangles) and cjTREC (represented by hearts) are generated during the DP thymocyte stage with a maximum of two copies in every cell. They are stably maintained within cells and diluted out after each cell division. Approximately 3 to 4 cell divisions occur before thymocytes containing sjTRECs emigrate into the periphery as RTEs (0.17 copies of sjTREC/RTE), whereas thymocytes harboring cjTREC experience 0 to 1 cell divisions when they are exported into the periphery as RTEs (1.33 copies of cjTREC/RTE). ${ }^{4}$ 


\section{[[TABLE LINES, EXCEPT FOR SPANNERS, ARE NOT JOURNAL STYLE.]] TABLE 1 Factors Influencing TREC Levels and TREC Concentrations in the Periphery}

TREC levels TREC concentrations

$\Uparrow$ Thymic output (RTEs)
$\Uparrow$ T-cell division
$\Uparrow T$-cell death
$\Uparrow$ TREC degradation
$\Uparrow$ Extrathymic T-cell generation

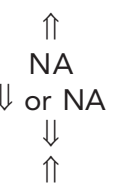

$\Uparrow$
$\Downarrow$
$\Downarrow$ or $\Uparrow$
$\Downarrow$
$\Downarrow$ or $\Uparrow$

Note: $\Uparrow$ : increase; $\Downarrow$ : decrease; NA: not affected.

\section{Thymus Versus T-Cell Dynamics}

As human RTEs cannot be measured experimentally, it is not feasible to estimate the contribution of the thymus to changes in TREC concentrations. Thymus transplantation and thymectomy, however, may reveal some insights into this issue. In patients with DiGeorge syndrome or those infected with HIV-1 who received transplantation of thymus tissue, increases in both $\mathrm{CD}^{+}$and $\mathrm{CD} 8^{+}$ TRECs are observed. 5,25 Thymectomy in humans results in a decrease in peripheral blood $\mathrm{CD}^{+}$and $\mathrm{CD}^{+}$TREC concentrations as compared with healthy controls, and TREC concentrations remain consistently lower after thymectomy performed 40 years earlier., ${ }^{4,8}$ Similar profound decreases in blood TREC concentrations are also observed in rhesus macaques, mice, and chickens after thymectomy for both $\mathrm{CD}^{+}$and $\mathrm{CD} 8^{+} \mathrm{T}$-cell compartments..$^{21,34,47}$ The above evidence indicates that the thymus does play a major role in regulating periphery TREC concentrations.

In contrast to the immediate decrease in TREC concentrations observed in thymectomized chickens, ${ }^{47}$ TREC decline has a lag of 3 to 7 months after thymectomy in humans $s^{8,30}$ and a lag of 2 weeks in mice. ${ }^{21}$ This phenomenon may be related to a small extrathymic generation of TRECs in humans and mice, whereas all $\mathrm{T}$ cells in chickens are generated within the thymus. ${ }^{47}$ Incomplete surgical removal of thymic tissue, thymectomy-induced prolongation of naive $\mathrm{T}$-cell half-life, or the long half-life of TRECs may also account for the delayed fall of TREC concentrations in thymectomized humans and mice.

Changes in T-cell division and death rates have been associated with variations in TREC concen- trations in the periphery. ${ }^{11,12}$ Unlike human RTEs which cannot be measured experimentally, several techniques are available to monitor peripheral $\mathrm{T}$ cell dynamics, including expression of the proliferation marker Ki67, ${ }^{11,12}$ BrdU labeling, ${ }^{48}$ and deuterated glucose labeling. ${ }^{49,50}$ These methods can estimate peripheral $\mathrm{T}$-cell division and death rates, which are very helpful in interpreting how $\mathrm{T}$-cell turnover influences TREC concentrations. Ki67 is expressed in cells that are in the cell division cycle. Peripheral blood T-cell division has been studied by flow cytometric measurements of Ki67 expression on T cells. ${ }^{11,12} \mathrm{Ki67}$, however, can only be detected in vitro, and it may be expressed by nondividing cells arrested in some phases of the cell cycle. ${ }^{51}$ BrdU is a substitute for thymidine in newly synthesized DNA that labels dividing cells in vivo. ${ }^{52} \mathrm{It}$ is considered too toxic for use in humans in vivo; it can, however, be used for ex vivo labeling of human cells. ${ }^{48}$ Deuterated glucose is a stable isotope-labeled metabolite that can be administered intravenously and incorporated into the DNA of dividing cells. ${ }^{49,50}$ This technique is devised for the direct measurement of cell kinetics in humans.

The key to interpreting TREC data is to quantify effects of thymic output, T-cell division, and death on TREC concentrations. Although Tcell division and $\mathrm{T}$-cell death can be measured experimentally, RTE levels cannot. In this situation, computational modeling can be an invaluable tool for integrating relevant biological elements into a system for study. ${ }^{10,12}$ We developed a mathematical model to describe the nonlinear dynamics of T cells and TRECs in the periphery. ${ }^{10}$ Through studying the parameters that govern thymic output, $\mathrm{T}$-cell division, and $\mathrm{T}$-cell death, respectively, we were able to address relative 
contributions of these three events to TREC concentrations. Our results indicate that, at any age, when these three events have a similar foldchange, thymic output and peripheral $\mathrm{T}$-cell division have the same potential to change TREC concentrations, whereas $\mathrm{T}$-cell death would affect TREC concentrations to a lesser extent. ${ }^{10}$

\section{TREC During Aging}

A gradual decline of TREC concentrations occurs with age in healthy people, ${ }^{4,39}$ as well as in rhesus macaques, sooty mangabeys, ${ }^{34}$ and mice. ${ }^{21}$ Experimental data show that Ki67 expression, which represents cell division, does not increase in either $\mathrm{CD}^{+}$ or $\mathrm{CD}^{+} \mathrm{T}$ cells in healthy individuals between the ages of 23 and 88 years. This suggests that a decrease in the TREC concentration during aging indeed reflects a decrease in thymic output of RTEs. ${ }^{11}$

We use our mathematical model to assess the decline in TREC concentrations during aging. ${ }^{10}$ As shown in Figure 6, when setting as constant either the $\mathrm{T}$-cell division rate (dashed line) or the $\mathrm{T}$-cell death rate (long dashed line), simulations of TREC concentrations have a similar trend of decline to the healthy controls (solid line). When thymic output is maintained at a fixed level, however, the simulated TREC concentration remains in a relatively steady state over 80 years (dotted line). This finding indicates that a decreased output of RTEs because of thymic involution predominantly induces the decline of TREC concentration during aging, which is consistent with experimental results. ${ }^{11}$ Interestingly, TREC concentration also remains in steady state when using both a constant $\mathrm{T}$-cell division rate and a constant $\mathrm{T}$-cell death rate (dot-dashed line). This suggests that declining thymic output will affect TREC concentration when accompanied by changes in either $\mathrm{T}$-cell division or death, ${ }^{53}$ which do occur during aging. ${ }^{54,55}$ Therefore, TREC concentration can represent thymic output of RTEs for healthy people during aging.

\section{TREC During HIV-1 Infection}

TREC concentrations in both $\mathrm{CD} 4^{+}$and $\mathrm{CD} 8^{+}$ $\mathrm{T}$ cells are significantly reduced during HIV-1

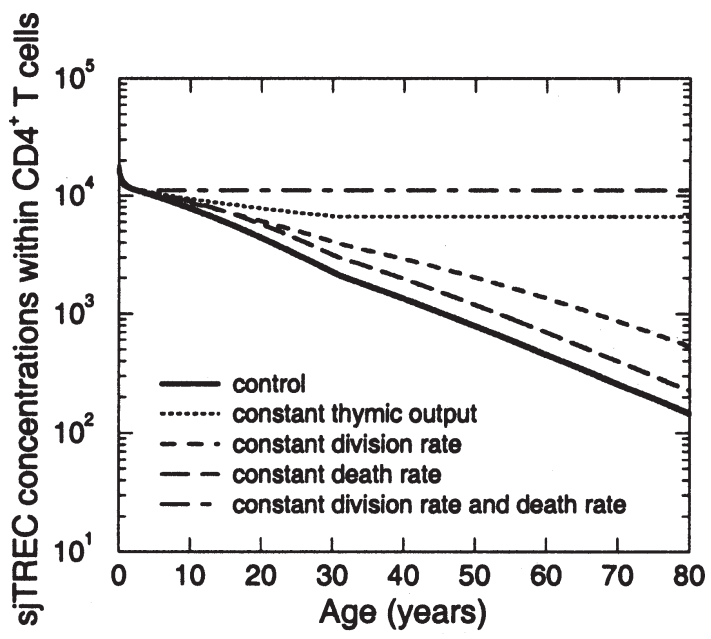

FIGURE 6. Simulation of sjTREC concentration within $\mathrm{CD}^{+} \mathrm{T}$ cells in healthy individuals during aging. The solid line represents simulation of healthy controls, and the other lines represent simulations using either thymic output at age 1 as constant (dotted line), or division rate at age 1 as constant (dashed line), or death rate at age 1 as constant (long dashed line), or division and death rates at age 1 as constants (dot-dashed line) over 80 years. (Modified and used with permission from Ref. 10.) 
infection, as compared with healthy controls. ${ }^{4,39,56}$ Controversy exists as to whether the decreased TREC concentration in the periphery is mainly caused by damaged thymic function or by increased T-cell division. ${ }^{4,10,12}$

Studies of HIV-1-infected patients indicate that the thymus can be infected by HIV -1, , $^{5-59}$ inducing decreases in naive $\mathrm{T}$-cell numbers, a reduced thymic volume, and thymic morphological changes. ${ }^{6-62}$ Thymic dysfunction and early thymic involution have been associated with rapid disease progression in a subset of infants infected perinatally with HIV-1. ${ }^{63-65}$ This evidence suggests that thymic function declines because of HIV-1 infection, which may contribute to the decline in TREC concentrations in the periphery.

HIV-1 infected patients have also been shown to have elevated T-cell division rates. $48,50,66,67$ Global activation of the immune system by HIV-1 has been suggested to lead to increases in T-cell proliferation. ${ }^{48} \mathrm{~T}$-cell dynamics in $\mathrm{CD}^{+}$and $\mathrm{CD} 8{ }^{+}$compartments, as well as naive and memory compartments, are different during HIV-1 infection. TREC concentrations similarly decrease in both $\mathrm{CD}^{+}{ }^{+}$and $\mathrm{CD} 8{ }^{+} \mathrm{T}$-cell populations during $\mathrm{HIV}-1$ infection ${ }^{4}$; division rates of $\mathrm{CD} 8^{+} \mathrm{T}$ cells, however, are elevated to higher levels, as compared with that of $\mathrm{CD}^{+} \mathrm{T}$ cells. ${ }^{66,67}$ This suggests that cell division contributes more to a decline in $\mathrm{CD} 8^{+} \mathrm{T}$-cell TREC concentrations as compared to $\mathrm{CD}^{+}{ }^{+} \mathrm{T}$-cell TREC concentrations. Experimental data from Ki67 labeling show that cell division increases in naive $\mathrm{CD} 8{ }^{+} \mathrm{T}$ cells but not in naive $\mathrm{CD}^{+} \mathrm{T}$ cells. This implies that a decrease in $\mathrm{CD}^{+}{ }^{+} \mathrm{T}$-cell TREC concentrations during HIV-1 infection could not result from an increased turnover of naive $\mathrm{CD}^{+}{ }^{+} \mathrm{T}$ cells, but rather result from a decreased thymic output. ${ }^{11}$ Another study applying the similar technique suggests, however, that divisions in both naive $\mathrm{CD}^{+}{ }^{+}$and $\mathrm{CD}^{+}{ }^{+} \mathrm{T}$ cells are significantly increased in HIV-1-infected patients. ${ }^{12}$ They claim that the rapid decline in TREC concentrations observed during HIV-1 infection is better explained by significant changes observed in peripheral T-cell division. These conflicting conclusions may derive from the fact that the latter study included "transitional" cells in the naive $\mathrm{CD} 4^{+}$group, which are actually transiting from naive to memory states. ${ }^{11,51}$ Nevertheless, delayed effects of thymectomy on TREC concentrations occurring for up to 3 months,, 830 and the rapid fall in TREC concentrations starting from early HIV-1 infection, ${ }^{39,56}$ more likely reflect an increase in $\mathrm{T}$-cell division rates than decreased thymic output during the first 3 months of HIV-1 infection.

Other factors may also explain TREC concentration decline during HIV-1 infection, such as increases in T-cell death rates ${ }^{48,50,66,67}$ and preferential redistribution of TREC-containing cells into lymph tissue. ${ }^{33}$ TREC concentrations in $\mathrm{CD}^{+} \mathrm{T}$ cells in lymph tissue are significantly higher than in the blood compartment, which may partially explain the decrease in TREC concentration observed in the peripheral blood of HIV-1-infected patients. ${ }^{33}$

Our mathematical model on TREC and T-cell dynamics again provides a systematic way to quantitatively analyze how the thymus and peripheral $\mathrm{T}$-cell turnover contribute to changes in peripheral TREC concentrations during HIV-1 infection. By incorporating experimental data on changes in T-cell division and death rates, and by fitting simulations with clinical data on both $\mathrm{T}$ cells and TREC concentrations, our model predicts changes in the rate of thymic output of RTEs during HIV-1 infection. ${ }^{10}$ Comparing fold-changes in the number of RTEs exported per day predicted by our model and $\mathrm{T}$-cell dynamic rates reported from literature, our analyses reveal that decreased thymic output primarily induces the decline of CD4+ $\mathrm{T}$-cell TREC concentrations, whereas increased peripheral $\mathrm{T}$-cell division and decreased thymic output both contribute to the decline in CD8+ ${ }^{+}$-cell TREC concentrations. ${ }^{10}$ Future improvements on this model application may include using $\mathrm{T}$-cell dynamic data during the acute phase, latent phase, and end phase of HIV-1 infection to predict RTE level changes during different disease stages. With these modifications, we could accurately explore factors contributing primarily to TREC decline over the entire course of HIV-1 infection.

\section{TREC During HIV-1 Treatment}

After undergoing highly active anti-retroviral therapy (HAART), a marked increase in TREC concentrations are observed in both children and 
adults. $4,56,68$ This may result from recovery of thymic function, ${ }^{4,56,69}$ reduction in T-cell proliferation and destruction, ${ }^{48-50,66}$ or release of TRECcontaining cells from lymphoid tissues. ${ }^{4}$

An early increase in naive $T$-cell numbers and increased thymic volume have been observed in HIV-1 patients during HAART. ${ }^{36,70,71}$ Larger thymic size with elevated CD4+ $\mathrm{T}$-cell counts and TREC concentrations are also observed together after HAART. ${ }^{9,71}$ TREC concentration correlates positively with the number of naive $\mathrm{T}$ cells, and negatively with age. ${ }^{72}$ Children have both earlier and greater increases in naive $\mathrm{T}$ cells and TREC concentrations than adults. ${ }^{39,56,73}$ One study using a mathematical model suggests that increased thymic output explains the increase in TREC concentrations during treatment of chronic HIV-1 infection. ${ }^{44}$ These data imply that recovery of thymic function could induce TREC concentration recovery in HIV-1-infected patients on HAART. On the other hand, proliferation and death in both $\mathrm{CD}^{+}$and $\mathrm{CD} 8^{+} \mathrm{T}$-cell populations are substantially reduced and return to near normal during treatment in HIV-1 patients. ${ }^{48-50,66}$ Therefore, the rebound of TREC concentration may be attributed to multiple factors. If data on $\mathrm{T}$-cell dynamics were available, together with TREC concentrations from patients undergoing HAART, our mathematical mode ${ }^{10}$ would have the potential to characterize primary factors that contribute to the recovery of TREC concentration.

\section{TREC in Other Clinical Settings}

TREC concentration has been used to represent thymic output of RTEs in other clinical settings, such as chemotherapy and hematopoietic stem cell transplantation. ${ }^{6,74}$ TREC concentration rises weeks after hematopoietic stem cell transplantation and correlates with the frequency of naive $T$ cells. ${ }^{6,74}$ A positive correlation between TREC concentration and broader TCR repertoires is also observed in transplant patients. ${ }^{6}$ This suggests that $\mathrm{T}$-cell regeneration requires residual thymic function in patients receiving hematopoietic stem cell transplantation, and increases in thymic output can contribute to observed increases in TREC concentrations.

\section{SUMMARY}

In this review, we summarize the recent literature on human thymic function and TREC concentration as a measurement of RTEs. The thymus clearly plays a key role in immunity, since it provides functional $\mathrm{T}$ cells to the periphery not only in children but also in adults, which is of great importance for the reconstitution of immune function during immunodeficiency conditions. TREC concentrations have been used widely as a measurement of RTEs, although the accuracy of this approach is under debate. Further studies that can directly measure TREC-containing $\mathrm{T}$ cells for proliferation and death, accurately characterize TREC concentrations and $\mathrm{T}$-cell dynamics in two distinct pools of naive and memory $\mathrm{T}$ cells, and evaluate TREC half-life are needed to clarify the value of using TREC concentration as a marker for thymic output. We suggest that T-cell turnover rates are the key to understanding TREC concentrations as a surrogate marker for RTEs. If peripheral $\mathrm{T}$-cell turnover remains relatively stable, then TREC concentration indeed reflects thymic output of RTEs. Mathematical models can be an invaluable tool to characterize factors leading to changes in TREC concentrations.

\section{ACKNOWLEDGMENTS}

This work was supported by National Institutes of Health HL62119 and The Whitaker Foundation to Denise E. Kirschner, and Rackham Predoctoral Fellowship to Ping Ye. We thank Dr. Victor DiRita and Dr. Rob de Boer for their helpful suggestions, and Vanessa Pherigo for her excellent art work.

\section{REFERENCES}

1. Mackall CL, Hakim FT, Gress RE. T-cell regeneration: all repertoires are not created equal. Immunol Today 1997; 18:245-251.

2. Haynes BF. HIV infection and the dynamic interplay between the thymus and the peripheral $\mathrm{T}$ cell pool. Clin Immunol 1999; 92:3-5.

3. Haynes BF, Markert ML, Sempowski GD, Patel DD, Hale LP. The role of the thymus in immune reconstitution in aging, bone marrow transplantation, and HIV-1 infection. Annu Rev Immunol 2000; 18:529-560. 
4. Douek DC, McFarland RD, Keiser PH, Gage EA, Massey JM, Haynes BF, Polis MA, Haase AT, Feinberg MB, Sullivan JL, Jamieson BD, Zack JA, Picker LJ, Koup RA. Changes in thymic function with age and during the treatment of HIV infection [see comments]. Nature 1998; 396:690-695.

5. Markert ML, Boeck A, Hale LP, Kloster AL, McLaughlin TM, Batchvarova MN, Douek DC, Koup RA, Kostyu DD, Ward FE, Rice HE, Mahaffey SM, Schiff SE, Buckley RH, Haynes BF. Transplantation of thymus tissue in complete DiGeorge syndrome. $\mathrm{N}$ Engl J Med 1999; 341:1180-1189.

6. Douek DC, Vescio RA, Betts MR, Brenchley JM, Hill BJ, Zhang L, Berenson JR, Collins RH, Koup RA. Assessment of thymic output in adults after haematopoietic stem-cell transplantation and prediction of T-cell reconstitution. Lancet 2000; 355:1875-1881.

7. Pido-Lopez J, Imami N, Aspinall R. Both age and gender affect thymic output: more recent thymic migrants in females than males as they age. Clin Exp Immunol 2001; 125:409-413.

8. Sempowski G, Thomasch J, Gooding M, Hale L, Edwards L, Ciafaloni E, Sanders D, Massey J, Douek D, Koup R, Haynes B. Effect of thymectomy on human peripheral blood $\mathrm{T}$ cell pools in myasthenia gravis. J Immunol 2001; 166:2808-2817.

9. Kolte L, Dreves AM, Ersboll AK, Strandberg C, Jeppesen DL, Nielsen JO, Ryder LP, Nielsen SD. Association between larger thymic size and higher thymic output in human immunodeficiency virusinfected patients receiving highly active antiretroviral therapy. J Infect Dis 2002; 185:1578-1585.

10. Ye P, Kirschner DE. Reevaluation of T cell receptor excision circles as a measure of human recent thymic emigrants. J Immunol 2002; 168:4968-4979. (Copyright 2002. The American Association of Immunologists, Inc.)

11. Douek DC, Betts MR, Hill BJ, Little SJ, Lempicki R, Metcalf JA, Casazza J, Yoder C, Adelsberger JW, Stevens RA, Baseler MW, Keiser P, Richman DD, Davey RT, Koup RA. Evidence for increased T cell turnover and decreased thymic output in HIV infection. J Immunol 2001; 167:6663-6668.

12. Hazenberg MD, Otto SA, Cohen Stuart JW, Verschuren MC, Borleffs JC, Boucher CA, Coutinho RA, Lange JM, Rinke de Wit TF, Tsegaye A, van Dongen JJ, Hamann DR, de Boer J, Miedema F. Increased cell division but not thymic dysfunction rapidly affects the $\mathrm{T}$-cell receptor excision circle content of the naive $\mathrm{T}$ cell population in HIV-1 infection [see comments]. Nat Med 2000; 6:1036-1042.

13. Haynes BF, Hale LP. The human thymus. A chimeric organ comprised of central and peripheral lymphoid components. [Corrected and republished article originally printed in Immunol Res 1998;18(2):6178.] Immunol Res 1998; 18:175-192.

14. Ritter MA, Palmer DB. The human thymic microenvironment: new approaches to functional analysis. Semin Immunol 1999; 11:13-21.
15. Steinmann GG, Klaus B, Muller-Hermelink HK. The involution of the ageing human thymic epithelium is independent of puberty. A morphometric study. Scand J Immunol 1985; 22:563-575.

16. Kraft DL, Weissman IL, Waller EK. Differentiation of $\mathrm{CD}^{-} 4^{-} 8^{-}$human fetal thymocytes in vivo: characterization of a CD3-4 $4^{+}$intermediate. J Exp Med 1993; 178:265-277.

17. Brearley S, Gentle TA, Baynham MI, Roberts KD, Abrams LD, Thompson RA. Immunodeficiency following neonatal thymectomy in man. Clin Exp Immunol 1987; 70:322-327.

18. Mackall CL, Fleisher TA, Brown MR, Andrich MP, Chen CC, Feuerstein IM, Horowitz ME, Magrath IT, Shad AT, Steinberg SM, et al. Age, thymopoiesis, and $\mathrm{CD} 4{ }^{+} \mathrm{T}$-lymphocyte regeneration after intensive chemotherapy. N Engl J Med 1995; 332:143-149.

19. Jamieson BD, Douek DC, Killian S, Hultin LE, Scripture-Adams DD, Giorgi JV, Marelli D, Koup RA, Zack JA. Generation of functional thymocytes in the human adult. Immunity 1999; 10:569-575.

20. Poulin JF, Viswanathan MN, Harris JM, Komanduri $\mathrm{KV}$, Wieder E, Ringuette N, Jenkins M, McCune JM, Sekaly RP. Direct evidence for thymic function in adult humans. J Exp Med 1999; 190:479-486.

21. Sempowski GD, Gooding ME, Liao HX, Le PT, Haynes BF. T cell receptor excision circle assessment of thymopoiesis in aging mice. Mol Immunol 2002; 38:841-848.

22. von Freeden-Jeffry U, Vieira P, Lucian LA, McNeil T, Burdach SE, Murray R. Lymphopenia in interleukin (IL)-7 gene-deleted mice identifies IL-7 as a nonredundant cytokine. J Exp Med 1995; 181:1519-1526.

23. Okamoto Y, Douek DC, McFarland RD, Koup RA. Effects of exogenous interleukin-7 on human thymus function. Blood 2002; 99:2851-2858.

24. Napolitano LA, Lo JC, Gotway MB, Mulligan K, Barbour JD, Schmidt D, Grant RM, Halvorsen RA, Schambelan M, McCune JM. Increased thymic mass and circulating naive CD4 T cells in HIV-1-infected adults treated with growth hormone. AIDS 2002; 16:1103-1111.

25. Markert ML, Hicks CB, Bartlett JA, Harmon JL, Hale LP, Greenberg ML, Ferrari G, Ottinger J, Boeck A, Kloster AL, McLaughlin TM, Bleich KB, Ungerleider RM, Lyerly HK, Wilkinson WE, Rousseau FS, Heath-Chiozzi ME, Leonard JM, Haase AT, Shaw GM, Bucy RP, Douek DC, Koup RA, Haynes BF, Bolognesi DP, Weinhold KJ. Effect of highly active antiretroviral therapy and thymic transplantation on immunoreconstitution in HIV infection. AIDS Res Hum Retroviruses 2000; 16:403-413.

26. Kong F, Chen $\mathrm{CH}$, Cooper MD. Thymic function can be accurately monitored by the level of recent $\mathrm{T}$ cell emigrants in the circulation. Immunity 1998; 8:97-104

27. Luettig B, Sponholz A, Heerwagen C, Bode U, Westermann J. Recent thymic emigrants (CD4+) con- 
tinuously migrate through lymphoid organs: within the tissue they alter surface molecule expression. Scand J Immunol 2001; 53:563-571.

28. Hosseinzadeh H, Goldschneider I. Recent thymic emigrants in the rat express a unique antigenic phenotype and undergo post-thymic maturation in peripheral lymphoid tissues. J Immunol 1993; 150:1670-1679.

29. Berzins SP, Boyd RL, Miller JF. The role of the thymus and recent thymic migrants in the maintenance of the adult peripheral lymphocyte pool. J Exp Med 1998; 187:1839-1848.

30. McFarland RD, Douek DC, Koup RA, Picker LJ. Identification of a human recent thymic emigrant phenotype. Proc Natl Acad Sci USA 2000; 97:4215-4220.

31. Hassan J, Reen DJ. Human recent thymic emigrantsidentification, expansion, and survival characteristics. J Immunol 2001; 167:1970-1976.

32. Kimmig S, Przybylski GK, Schmidt CA, Laurisch K, Mowes B, Radbruch A, Thiel A. Two subsets of naive $\mathrm{T}$ helper cells with distinct $\mathrm{T}$ cell receptor excision circle content in human adult peripheral blood. J Exp Med 2002; 195:789-794.

33. Nokta MA, Li XD, Al-Harthi L, Nichols J, Pou A, Asmuth D, Landay A, Pollard RB. Entrapment of recent thymic emigrants in lymphoid tissues from HIV-infected patients: association with HIV cellular viral load. AIDS 2002; 16:2119-2127.

34. Sodora DL, Douek DC, Silvestri G, Montgomery L, Rosenzweig M, Igarashi T, Bernacky B, Johnson RP, Feinberg MB, Martin MA, Koup RA. 2000 Quantification of thymic function by measuring $T$ cell receptor excision circles within peripheral blood and lymphoid tissues in monkeys. Eur J Immunol 30:1145-1153.

35. Hassan J, Reen DJ. IL-7 and homeostasis of recent thymic emigrants. Trends Immunol 2002; 23:126-127.

36. Vigano A, Vella S, Saresella M, Vanzulli A, Bricalli D, Di Fabio S, Ferrante P, Andreotti M, Pirillo M, Dally LG, Clerici M, Principi N. Early immune reconstitution after potent antiretroviral therapy in $\mathrm{HIV}$-infected children correlates with the increase in thymus volume. AIDS 2000; 14:251-261.

37. Smith KY, Valdez H, Landay A, Spritzler J, Kessler HA, Connick E, Kuritzkes D, Gross B, Francis I, McCune JM, Lederman MM. Thymic size and lymphocyte restoration in patients with human immunodeficiency virus infection after 48 weeks of zidovudine, lamivudine, and ritonavir therapy. J Infect Dis 2000; 181:141-147.

38. Kolte L, Strandberg C, Dreves AM, Ersboll AK, Jeppesen DL, Ryder LP, Nielsen SD. Thymic involvement in immune recovery during antiretroviral treatment of HIV infection in adults; comparison of $\mathrm{CT}$ and sonographic findings. Scand J Infect Dis 2002; 34:668-672.

39. Zhang L, Lewin SR, Markowitz M, Lin HH, Skulsky E, Karanicolas R, He Y, Jin X, Tuttleton S, Vesanen M, Spiegel H, Kost R, van Lunzen J, Stellbrink HJ, Wolinsky S, Borkowsky W, Palumbo P, Kostrikis LG, Ho DD. Measuring recent thymic emigrants in blood of normal and HIV-1-infected individuals before and after effective therapy. J Exp Med 1999; 190:725-732.

40. Chen ZW, Chen CC, Lekutis C, Shen L, Zhou D, Halloran M, Li J, Sodroski J, Lee-Parritz D, Letvin NL. $\mathrm{T}$ cell receptor $\mathrm{V}$ beta repertoire in an acute infection of rhesus monkeys with simian immunodeficiency viruses and a chimeric simian-human immunodeficiency virus. J Exp Med 1995; 182:21-31.

41. Verschuren MC, Wolvers-Tettero IL, Breit TM, Noordzij J, van Wering ER, van Dongen JJ. Preferential rearrangements of the $T$ cell receptor-delta-deleting elements in human T cells. J Immunol 1997; 158:1208-1216.

42. van Dongen JJ, Wolvers-Tettero IL. Analysis of immunoglobulin and T cell receptor genes. Part II: Possibilities and limitations in the diagnosis and management of lymphoproliferative diseases and related disorders. Clin Chim Acta 1991; 198:93-174.

43. Janeway CA, Travers P. Immunobiology, the immune system in health and disease. 3rd ed. New York: Garland Publishing, 1997.

44. Lewin SR, Ribeiro RM, Kaufmann GR, Smith D, Zaunders J, Law M, Solomon A, Cameron PU, Cooper D, Perelson AS. Dynamics of T cells and TCR excision circles differ after treatment of acute and chronic HIV infection. J Immunol 2002; 169:4657-4666.

45. Al-Harthi L, Marchetti G, Stefan CM, Mffens C, Poulin J, Sekaly R, Landay A. Detection of T cell receptor circles (TRECs) as biomarkers for de novo $\mathrm{T}$ cell synthesis using a quantitative polymerase chain reaction-enzyme linked immunosorbent assay (PCRELISA). J Immunol Methods 2000; 237:187-197.

46. Loeffler J, Bauer R, Hebart H, Douek DC, Rauser G, Bader P, Einsele H. Quantification of T-cell receptor excision circle DNA using fluorescence resonance energy transfer and the LightCycler system. J Immunol Methods 2002; 271:167-175.

47. Kong FK, Chen CL, Six A, Hockett RD, Cooper MD. T cell receptor gene deletion circles identify recent thymic emigrants in the peripheral $\mathrm{T}$ cell pool. Proc Natl Acad Sci USA 1999; 96:1536-1540.

48. Lempicki RA, Kovacs JA, Baseler MW, Adelsberger JW, Dewar RL, Natarajan V, Bosche MC, Metcalf JA, Stevens RA, Lambert LA, Alvord WG, Polis MA, Davey RT, Dimitrov DS, Lane HC. Impact of $\mathrm{HIV}-1$ infection and highly active antiretroviral therapy on the kinetics of $\mathrm{CD}^{+}{ }^{+}$and $\mathrm{CD} 8^{+} \mathrm{T}$ cell turnover in HIV-infected patients. Proc Natl Acad Sci USA 2000; 97:13778-13783.

49. McCune JM, Hanley MB, Cesar D, Halvorsen R, Hoh R, Schmidt D, Wieder E, Deeks S, Siler S, Neese R, Hellerstein M. Factors influencing T-cell turnover in HIV-1-seropositive patients [see comments]. J Clin Invest 2000; 105:R1-R8.

50. Hellerstein M, Hanley MB, Cesar D, Siler S, Papageorgopoulos C, Wieder E, Schmidt D, Hoh R, Neese R, Macallan D, Deeks S, McCune JM. Directly measured kinetics of circulating $\mathrm{T}$ lymphocytes in 
normal and HIV-1-infected humans. Nat Med 1999; 5:83-89.

51. Grossman Z, Paul WE. The impact of HIV on naive T-cell homeostasis. Nat Med 2000; 6:976-977.

52. Mohri H, Bonhoeffer S, Monard S, Perelson AS, Ho DD. Rapid turnover of $\mathrm{T}$ lymphocytes in SIV-infected rhesus macaques. Science 1998; 279: 1223-1227.

53. Dutilh BE, de Boer RJ. Decline in excision circles requires homeostatic renewal or homeostatic death of naive T cells. J Theor Biol 2003 (in press).

54. Chakrabarti LA, Lewin SR, Zhang L, Gettie A, Luckay A, Martin LN, Skulsky E, Ho DD, ChengMayer C, Marx PA. Age-dependent changes in T cell homeostasis and SIV load in sooty mangabeys. J Med Primatol 2000; 29:158-165.

55. Mackall CL, Granger L, Sheard MA, Cepeda R, Gress RE. T-cell regeneration after bone marrow transplantation: differential CD45 isoform expression on thymic-derived versus thymic-independent progeny. Blood 1993; 82:2585-2594.

56. Douek DC, Koup RA, McFarland RD, Sullivan JL, Luzuriaga K. Effect of HIV on thymic function before and after antiretroviral therapy in children. J Infect Dis 2000; 181:1479-1482.

57. Su L, Kaneshima H, Bonyhadi M, Salimi S, Kraft D, Rabin L, McCune JM. HIV-1-induced thymocyte depletion is associated with indirect cytopathogenicity and infection of progenitor cells in vivo. Immunity $1995 ; 2: 25-36$.

58. Cameron PU, Lowe MG, Sotzik F, Coughlan AF, Crowe SM, Shortman K. The interaction of macrophage and non-macrophage tropic isolates of HIV-1 with thymic and tonsillar dendritic cells in vitro. J Exp Med 1996; 183:1851-1856.

59. Braun J, Valentin H, Nugeyre MT, Ohayon H, Gounon P, Barre-Sinoussi F. Productive and persistent infection of human thymic epithelial cells in vitro with HIV-1. Virology 1996; 225:413-418.

60. Roederer M, De Rosa SC, Watanabe N, Herzenberg LA. Dynamics of fine T-cell subsets during HIV disease and after thymic ablation by mediastinal irradiation. Semin Immunol 1997; 9:389-396.

61. Rosenzweig M, Clark DP, Gaulton GN. Selective thymocyte depletion in neonatal HIV-1 thymic infection. AIDS 1993; 7:1601-1605.

62. Papiernik M, Brossard Y, Mulliez N, Roume J, Brechot C, Barin F, Goudeau A, Bach JF, Griscelli C, Henrion $\mathrm{R}$, et al. Thymic abnormalities in fetuses aborted from human immunodeficiency virus type 1 seropositive women. Pediatrics 1992; 89:297-301.

63. Kourtis AP, Ibegbu C, Nahmias AJ, Lee FK, Clark WS, Sawyer MK, Nesheim S. Early progression of disease in HIV-infected infants with thymus dysfunction. [Published erratum appears in N Engl J Med
1997 Feb 20;336(8):595.] N Engl J Med 1996; 335:1431-1436.

64. Kirschner DE, Mehr R, Perelson AS. Role of the thymus in pediatric HIV-1 infection. J Acquir Immune Defic Syndr Hum Retrovirol 1998; 18:95-109.

65. Ye P, Kourtis AP, Kirschner DE. The effects of different HIV-1 strains on human thymic function. AIDS Res Hum Retroviruses 2002; 18:1239-1251.

66. Mohri H, Perelson AS, Tung K, Ribeiro RM, Ramratnam B, Markowitz M, Kost R, Hurley A, Weinberger L, Cesar D, Hellerstein MK, Ho DD. Increased turnover of $\mathrm{T}$ lymphocytes in $\mathrm{HIV}-1$ infection and its reduction by antiretroviral therapy. J Exp Med 2001; 194:1277-1287.

67. Sachsenberg N, Perelson AS, Yerly S, Schockmel GA, Leduc D, Hirschel B, Perrin L. Turnover of CD4+ and CD8+ T lymphocytes in HIV-1 infection as measured by Ki-67 antigen. J Exp Med 1998; 187:1295-1303.

68. Clerici M, Saresella M, Trabattoni D, Ferrante P, Vanzulli A, Vigano A. Thymic volume predicts longterm immune reconstitution in HIV-infected children treated with highly active antiretroviral therapy. AIDS 2002; 16:2219-2221.

69. Ye P, Kourtis AP, Kirschner DE. Reconstitution of thymic function in HIV-1 patients treated with highly active anti-retroviral therapy. Clin Immunol 2003; 106:95-105.

70. Gibb DM, Newberry A, Klein N, de Rossi A, GroschWoerner I, Babiker A. Immune repopulation after HAART in previously untreated HIV-1-infected children. Paediatric European Network for Treatment of AIDS (PENTA) Steering Committee [letter]. Lancet 2000; 355:1331-1332.

71. Franco JM, Rubio A, Martinez-Moya M, Leal M, Merchante E, Sanchez-Quijano A, Lissen E. T-cell repopulation and thymic volume in $\mathrm{HIV}$-1-infected adult patients after highly active antiretroviral therapy. Blood 2002; 99:3702-3706.

72. Chavan S, Bennuri B, Kharbanda M, Chandrasekaran A, Bakshi S, Pahwa S. Evaluation of T cell receptor gene rearrangement excision circles after antiretroviral therapy in children infected with human immunodeficiency virus. J Infect Dis 2001; 183:1445-1454.

73. Franco JM, Leon-Leal JA, Leal M, Cano-Rodriguez A, Pineda JA, Macias J, Rubio A, Rey C, Sanchez B, Lissen E. CD4+ and CD8+ T lymphocyte regeneration after anti-retroviral therapy in HIV-1-infected children and adult patients. Clin Exp Immunol 2000; 119:493-498.

74. Weinberg K, Blazar BR, Wagner JE, Agura E, Hill BJ, Smogorzewska M, Koup RA, Betts MR, Collins RH, Douek DC. Factors affecting thymic function after allogeneic hematopoietic stem cell transplantation. Blood 2001; 97:1458-1466. 